\title{
Simultaneous Uniportal video-assisted thoracic surgery of bilateral pulmonary nodules
}

Shengcheng Lin ${ }^{1 \dagger}$, Chenglin Yang ${ }^{1 \dagger}$, Xiaotong Guo ${ }^{1}$, Yafei Xu², Lixu Wang ${ }^{1}$, Zhe Wang ${ }^{1}$, Xin Yu', Chunguang Wang ${ }^{1}$ and Zhentao $\mathrm{Yu}^{1 *}$

\begin{abstract}
Background: Surgical resection is an appropriate treatment option for synchronous bilateral pulmonary nodules with ground-glass opacities. The applicability of simultaneous uniportal video-assisted thoracic surgery is not fully understood. We evaluated the feasibility and safety of performing such surgeries at our hospital.

Methods: Clinical data of 35 patients who underwent simultaneous bilateral pulmonary resection with uniportal video-assisted thoracic surgery at our hospital were reviewed retrospectively.

Results: Simultaneous bilateral pulmonary resection with uniportal video-assisted thoracic surgery was performed for 35 patients (15 men, 20 women); 97 nodules were operated on, and the average nodule diameter was $11.4 \mathrm{~mm}$ (range, 1-38 mm). Computerized tomography showed that most nodules had ground-glass opacity (52/97, 53.6\%); solid nodules $(24 / 97,24.7 \%)$ and nodules with mixed ground-glass opacity $(21 / 97,21.7 \%)$ were noted. Surgical resection included lobar-sublobar resection $(11 / 35,31.4 \%)$ and sublobar-sublobar resection $(24 / 35,68.6 \%)$. Wound infection and postoperative 30-day mortality were not observed. Pneumonia was the major postoperative complication, with a higher incidence in the lobar-sublobar group $(6 / 10,60 \%)$ than in the sublobar-sublobar group $(4 / 25,16 \% ; P=0.016)$. Pneumonia did not correlate with operative time (mean, $262.3 \pm 108.1$ vs. $261.9 \pm 87.5$ min, $P=0.991$ ), duration of chest drainage (mean, $7.0 \pm 4.0$ vs $5.4 \pm 2.1$ days, $P=0.124$ ), and postoperative hospital stay (mean, $10.2 \pm 3.6$ vs $10.2 \pm 6.4$ days, $P=0.978$ ). The mean follow-up time was 8 (range, $3-22$ ) months. Recurrence of primary lung cancer or mortality was not noted at the final follow-up.
\end{abstract}

Conclusions: Simultaneous bilateral pulmonary resection with uniportal video-assisted thoracic surgery is feasible and safe for appropriate patients. Simultaneous lobar-sublobar pulmonary resection for bilateral nodules can increase the risk of developing pneumonia.

Keywords: Simultaneous, Bilateral, Pulmonary nodules, Uniportal video-assisted thoracic surgery, Postoperative complications

\footnotetext{
* Correspondence: yuzhentao@chcamssz.ac.cn

${ }^{\dagger}$ Shengcheng Lin and Chenglin Yang contributed equally to this work.

'Department of Thoracic Surgery, National Cancer Center/National Clinical Research Center for Cancer/Cancer Hospital and Shenzhen Hospital, Chinese Academy of Medical Sciences and Peking Union Medical College, Shenzhen 518116, China

Full list of author information is available at the end of the article
}

(c) The Author(s). 2021 Open Access This article is licensed under a Creative Commons Attribution 4.0 International License, which permits use, sharing, adaptation, distribution and reproduction in any medium or format, as long as you give appropriate credit to the original author(s) and the source, provide a link to the Creative Commons licence, and indicate if changes were made. The images or other third party material in this article are included in the article's Creative Commons licence, unless indicated otherwise in a credit line to the material. If material is not included in the article's Creative Commons licence and your intended use is not permitted by statutory regulation or exceeds the permitted use, you will need to obtain permission directly from the copyright holder. To view a copy of this licence, visit http://creativecommons.org/licenses/by/4.0/ The Creative Commons Public Domain Dedication waiver (http://creativecommons.org/publicdomain/zero/1.0/) applies to the data made available in this article, unless otherwise stated in a credit line to the data. 


\section{Background}

Due to the popularization of thin-section computed tomography (CT) and the increasing awareness of people's health examinations, an increasing number of synchronous bilateral pulmonary nodules (SMBPNs) have been found, mostly ground-glass opacities (GGO) [1, 2]. It is necessary to distinguish the nature of multiple pulmonary nodules-benign or malignant-and whether it is a multifocal primary lung cancer or intrapulmonary metastasis. Therefore, it can be challenging to choose the appropriate treatment option.

Surgical resection has become the main treatment for SMBPNs highly suspected to be synchronous multiple primary lung cancers (SMPLCs). A 35-92\% 3-year survival rate of SMPLCs has been reported in the literature $[3,4]$. Simultaneous bilateral pulmonary resections have been considered to have high invasiveness and mortality, and their safety is still debated $[3,5]$. Since Japanese researchers initially reported simultaneous bilateral pulmonary resections 10 years ago, there have been several studies of simultaneous operations for SMPLCs [2, 6]. A few studies have reported the efficacy of uniportal videoassisted thoracic surgery (VATS) in the treatment of SMPLCs. Here, we summarize our hospital's experience with the feasibility and safety of simultaneous uniportal video-assisted thoracic surgery in the treatment of SMPLCs within the last 2 years, particularly evaluating the associated postoperative complications.

\section{Methods}

\section{Patients and clinical features}

This study was approved by the Cancer Hospital and Shenzhen Hospital, Chinese Academy of Medical Sciences and Peking Union Medical College Institutional Review Board of Clinical Research (NO.: 2020-173). The study conformed to the provisions of the Declaration of Helsinki. Due to the retrospective study design, the informed consent requirement was waived. Clinical data of 35 patients who underwent simultaneous bilateral pulmonary resection by uniportal VATS at our hospital from April 2018 to January 2020 were reviewed retrospectively.

An institutional oncologic multidisciplinary meeting (attended by experts from the surgery, radiation oncology, and medical oncology departments) was held to evaluate preoperative treatment strategies. All patients in this study were cN0 without distant metastasis, and no patients demonstrated pathologic mediastinal lymph node.

Imaging characteristics and the consolidation/tumor ratio (CTR) of tumors were evaluated using thinsection CT. In our research, the computed tomography (CT) features of tumors were divided into the following three subgroups according to the imaging characteristics and the CTR of the tumors: pure GGO
(pGGO) group, CTR =0; mixed GGO (mGGO) group, CTR $>0$ and CTR $<1$; solid pulmonary nodules (sPNs) group, CTR $=1$ [1].

The TNM staging depended on the most advanced stage of all nodules in each primary lung cancer case. All postoperative histopathologic-proven adenocarcinomas were reclassified based on the new classification proposed by the International Association for the Study of Lung Cancer [7]. The pathologic criteria for diagnosis of SMPLCs in our hospital were based on the MartiniMelamed criteria [8]/Antakli criteria [9].

Diagnosis of postoperative pulmonary complications was performed based on EPCO-recommended definitions [10], where the definition of pneumonia includes at least one of the following items: infiltration, consolidation, and cavitation; plus at least one of the following: fever $>38^{\circ} \mathrm{C}$ without other cause, white cell count $<4$ or $>12 \times 10^{9} / \mathrm{L}$, age $>70$ years with altered mental status without other cause; plus at least two of the following: new purulent/changed sputum, increased secretions/suctioning, new/worse cough/dyspnea/tachypnea, rales/ bronchial breath sounds, and worsening gas exchange.

\section{Surgical procedure}

Simultaneous bilateral pulmonary resection by uniportal VATS was performed by the same team of surgeons and anesthetists using double-lumen endotracheal intubation. Pulmonary resection procedures were selected based on the size, location, and TSCT characteristics of tumors, as well as the performance status and pulmonary function testing. The sPNs or mGGO (CTR $>0.5$ ) were usually resected by lobectomy, whereas pGGO or mGGO (CTR < 0.5) were usually resected by segmentectomy or wedge resection. For patients with insufficient pulmonary reserve or poor performance, segmentectomy or wedge resection was selected instead of lobectomy. The priority for surgical resection was given to the side with a smaller resection range, and the right side was chosen in cases where both sides were similar.

\section{Follow-up}

All patients were followed up with chest CT and serum tumor markers (pro-gastrin-releasing peptide, carcinoembryonic antigen, cytokeratin 19 fragments, neuronspecific enolase, carbohydrate antigen, and alphafetoprotein) every 3 months and with cranial MRI and abdominal CT (including adrenals) every half year, and whenever necessary with positive symptoms at our clinic.

\section{Statistical analysis}

Continuous variables are presented as the mean and standard deviation and median and range; categorical variables are presented as numbers and percentages. To 
compare the postoperative course according to perioperative characteristics, Mann-Whitney test was used for quantitative variables, and the $\chi^{2}$ test or Fisher test was used for qualitative variables. SPSS, version 20 for Windows (IBM Corp, Armonk, NY) was used for statistical analysis. A $P$ value $<0.05$ was considered statistically significant.

\section{Results}

\section{Clinical characteristics}

Simultaneous bilateral pulmonary resection by uniportal VATS was performed in 35 patients ( 2 of the 37 patients did not have complete follow-up data). Our patients' cohort comprised 15 men and 20 women, with mean age $60.2 \pm 8.9$ [range, $42-75$ ] years. Three male patients had a history of smoking, and eight patients had comorbidities, including diabetes mellitus $(n=3)$, hypertension $(n=1)$, tuberculosis $(n=2)$, coronary heart disease $(n=$ $1)$, and diabetes mellitus combined with hypertension $(n=1)$. The mean preoperative-forced expiratory volume in $1 \mathrm{~s}$ (FEV 1) was $2486.9 \mathrm{~mL}$ (range, $1680-4560 \mathrm{~mL}$ ), and the FEV 1 mean forced vital capacity (FVC) was 91.0\% (range, 75.7-99.9\%).

Ninety-seven nodules were operated on, and the average nodule diameter was $11.4 \mathrm{~mm}$ (range, $1-38 \mathrm{~mm}$ ). TS CT revealed that most nodules were pGGO (52/97, $53.6 \%$ ), followed by sPNs $(24 / 97,24.7 \%)$ and mGGO (21/97, 21.7\%) nodules. In all cases, the performance status values ranged from 0 to 1 (Table 1 ).

\section{Surgery and pathology}

All patients underwent bilateral $3-4 \mathrm{~cm}$ incisions in the fourth (for upper lobar/sublobar resection in right lung) or fifth (for other pulmonary resection) interspace between the posterior and middle axillary line. A 20F silicone chest tube was placed in the same incision through a muscle tunnel. Lobar-sublobar (L-SL) resection (11/35, $31.4 \%)$ included lobectomy and contralateral segmentectomy $(7 / 35,20.0 \%)$, lobectomy and contralateral wedge resection $(3 / 35,8.6 \%)$, and lobectomy and contralateral multiple sublobar resection (segmentectomy and wedge resection) $(1 / 35,2.8 \%)$. Sublobar-sublobar (SL-SL) resection $(24 / 35,68.6 \%)$ included segmentectomy and contralateral segmentectomy $(14 / 35,40.0 \%)$, and multiple wedge resection $(10 / 35,28.6 \%)$. The mean duration of surgery and blood loss was $262.7 \pm 90.4$ (range, 116-478) min and $104 \pm 110.3 \mathrm{~mL}$ (range, $20-600 \mathrm{~mL}$ ), respectively.

Postoperative histopathologic diagnoses were made based on the Martini-Melamed criteria [8] and Antakli criteria [9]. The selected patients had SMPLCs (23/35, $65.7 \%)$, single primary lung cancer $(8 / 35,22.9 \%)$, bilateral atypical adenomatous hyperplasia (AAH) (1/35, $2.8 \%)$, and bilateral benign nodules $(3 / 35,8.6 \%)$. All patients with primary lung cancer were classified as IA1
Table 1 Clinical characteristics $(N=35)$

\begin{tabular}{ll}
\hline Variable & $\begin{array}{l}\text { Mean } \pm \text { SD (range) or } \\
\text { No. (\%) }\end{array}$ \\
\hline Age (year) & $60.2 \pm 8.9(42-75)$ \\
Sex & $15(42.9)$ \\
Male & $20(57.1)$ \\
Female & \\
Smoking history & $3(8.6)$ \\
Yes & $32(91.4)$ \\
No & \\
Comorbidity & $4(11.4)$ \\
Diabetes mellitus & $2(5.7)$ \\
Hypertension & $2(5.7)$ \\
Tuberculosis & $1(2.8)$ \\
Coronary heart disease & \\
Pulmonary function & $2486.9 \pm 644.3(1680-4560)$ \\
Forced expiratory volume in 1s & $91.0 \pm 7.4(74.5-99.9)$ \\
FEV1 mean forced vital capacity & \\
Number of tumors & $14(40)$ \\
$>2$ & $21(60)$ \\
$<2$ & $52(53.6)$ \\
CF & $21(21.7)$ \\
pGGO & $24(24.7)$ \\
mPNG & \\
\hline &
\end{tabular}

FEV1 preoperative-forced expiratory volume in $1 \mathrm{~s}, C F$ classification, $p G G O$ pure ground-glass opacity, $m G G O$ mixed GGO, sPNs solid pulmonary nodules

(10/35, 28.6\%), IA2 (9/35, 25.7\%), IA3 (8/35, 22.9\%), IB $(1 / 35,2.8 \%)$, IIB $(1 / 35,2.8 \%)$, and IIIA $(1 / 35,2.8 \%)$. The most advanced stage of one patient with lung cancer was adenocarcinoma in situ (AIS). One patient with a pstage IIIA disease had T3 N1 cancer.

All nodules included invasive adenocarcinoma (53/97, $54.7 \%)$, minimally invasive adenocarcinoma (MIA) (8/97, $8.2 \%)$, AIS $(8 / 97,8.2 \%)$, AAH $(8 / 97,8.2 \%)$, and benign nodules (20/97, 20.7\%). Postoperative histopathologic examination revealed that $71.1 \%(69 / 97)$ of nodules were lung adenocarcinoma, with $39.2 \%$ of those nodules being pGGO (38/97), followed by $17.5 \%$ mGGO (17/97), and 14.4\% sPNs (14/97) (Table 2).

\section{Postoperative course}

No wound infection and postoperative 30-day mortality occurred. The average time interval for chest tube placement and postoperative hospital stay was $5.8 \pm 2.7$ (range, 3-14) days and $10.3 \pm 5.7$ (range, 5-35) days, and the median was 5 days and 8 days, respectively. Postoperative complications [10] included pneumonia $(n=6)$, air leak $(n=1)$, atrial fibrillation $(n=2)$, and pneumonia combined with air leak $(n=1)$. We analyzed several 
Table 2 Surgical and pathologic characteristics $(N=35)$

\begin{tabular}{|c|c|c|c|c|c|c|}
\hline \multicolumn{3}{|l|}{ Variable } & \multicolumn{4}{|c|}{ No. (\%) } \\
\hline \multicolumn{7}{|c|}{ Resection (right/left) } \\
\hline \multicolumn{3}{|l|}{ L/S-W } & \multicolumn{4}{|l|}{$1(2.8)$} \\
\hline \multicolumn{3}{|l|}{$\mathrm{L} / \mathrm{S}$} & \multicolumn{4}{|l|}{$7(20.0)$} \\
\hline \multicolumn{3}{|l|}{ L/W } & \multicolumn{4}{|l|}{$3(8.6)$} \\
\hline \multicolumn{3}{|l|}{$S / S$} & \multicolumn{4}{|c|}{$14(40.0)$} \\
\hline \multicolumn{3}{|l|}{ W/W } & \multicolumn{4}{|c|}{$10(28.6)$} \\
\hline \multicolumn{7}{|c|}{ Postoperative histopathologic } \\
\hline \multicolumn{3}{|l|}{ SMPLCS } & \multicolumn{4}{|c|}{$23(65.7)$} \\
\hline \multicolumn{3}{|c|}{ Single primary lung cancer } & \multicolumn{4}{|l|}{$8(22.9)$} \\
\hline \multicolumn{3}{|c|}{ Bilateral AAH } & \multicolumn{4}{|l|}{$1(2.8)$} \\
\hline \multicolumn{3}{|c|}{ Bilateral benign nodules } & \multicolumn{4}{|l|}{$3(8.6)$} \\
\hline \multicolumn{7}{|l|}{ P-stage } \\
\hline \multicolumn{3}{|l|}{$|A|$} & \multicolumn{4}{|c|}{$10(28.6)$} \\
\hline \multicolumn{3}{|l|}{ IA2 } & \multicolumn{4}{|l|}{$9(25.7)$} \\
\hline \multicolumn{3}{|l|}{ IA3 } & \multicolumn{4}{|l|}{$8(22.9)$} \\
\hline \multicolumn{3}{|l|}{ IB } & \multicolumn{4}{|l|}{$1(2.8)$} \\
\hline \multicolumn{3}{|l|}{$\| \mathrm{B}$} & $1(2.8)$ & & & \\
\hline$\| \mathrm{A}$ & & & $1(2.8)$ & & & \\
\hline Others & & & $5(14.4)$ & & & \\
\hline Pathology & $\mathrm{l} \%$ & & & & & \\
\hline & $\mid A^{a}$ & MIA & AIS & $\mathrm{BN}$ & AAH & Total \\
\hline $\mathrm{CF} \mathrm{n/ \%}$ & & & & & & \\
\hline pGGO & $25(25.8)$ & $7(7.2)$ & $6(6.2)$ & $8(8.2)$ & $6(6.2)$ & $52(53.6)$ \\
\hline mGGO & $15(15.5)$ & $1(1.0)$ & $1(1.0)$ & $3(3.2)$ & $1(1.0)$ & $21(21.7)$ \\
\hline sPNs & $13(13.4)$ & 0 & $1(1.0)$ & $9(9.5)$ & $1(1.0)$ & $24(24.9)$ \\
\hline Total & $53(54.7)$ & $8(8.2)$ & $8(8.2)$ & $20(20.7)$ & $8(8.2)$ & $97(100)$ \\
\hline
\end{tabular}

$L$ lobectomy, $S$ segmentectomy, $W$ wedge resection, SMPLC synchronous multiple primary lung cancers, $A A H$ atypical adenomatous hyperplasia; Others, including adenocarcinoma in situ, bilateral AAH and other benign diseases. $I A^{a}$ invasive adenocarcinoma, MIA minimally invasive adenocarcinoma, AIS adenocarcinoma in situ, $B N$ benign nodules, $C F$ classification, $p G G O$ pure ground-glass opacity, $m G G O$ mixed GGO, sPNs solid pulmonary nodules

preoperative variables in accordance with the operative time, days of drainage, postoperative hospital stay, and rate of complications (Table 3). Pneumonia was the main postoperative complication. The incidence of pneumonia in the L-SL group $(6 / 10,60 \%)$ was higher than in the SL-SL group $(4 / 25,16 \% ; P=0.016)$; however, this did not correlate with the operative time (mean, $262.3 \pm 108.1$ vs. $261.9 \pm 87.5 \mathrm{~min}, P=0.991$ ), the time of chest drains (mean, $7.0 \pm 4.1$ vs. $5.4 \pm 2.1$ days, $P=0.124$ ), and postoperative hospital stay (mean, $10.2 \pm 3.6$ vs. $10.2 \pm 6.4$ days, $P=0.978$ ) (Table 3 ).

\section{Follow-up and survival}

The mean follow-up time was 8 (range, 3-22) months. There was no recurrence of primary lung cancer or death at final follow-up.

\section{Discussion}

In 1898, a patient with multiple primary cancers was reported by Billroth [11]; however, the concept of multiple primary lung cancers (MPLCs) was first described by Beyreuther in 1924 [11]. Martini and Melamed [8] published the first diagnostic criteria in 1975, and Antakli et al. [9] supplemented the diagnostic criteria for second primary lung cancer in 1995 and incorporated elements of the new international multidisciplinary lung adenocarcinoma classification [12]. According to these criteria, MPLCs include two subsets frequently referred to as SMPLCs and metachronous multiple primary lung cancers (MMPLCs).

Due to diagnostic radiographic techniques and the introduction of helical CT in the screening of lung cancers, an increasing number of SMBPNs with GGO components have been identified, and many have proven to be SMPLCs. The incidence of SMPLCs in the reported literature varies from 0.7 to $6.1 \%$ of all lung cancer cases $[3,13]$. According to our data, postoperative histopathology revealed that $65.7 \%$ of the cases had SMPLCs (23/ $35), 22.9 \%$ had single primary lung cancer (8/35), 2.86\% had bilateral AAH (1/35), and 8.6\% had bilateral benign nodules (3/35). The high incidence of SMPLCs is due to the preoperative multidisciplinary meeting of the institutional oncology team and the careful selection of therapeutic strategies, especially for SMBPNs containing GGO components. Hence, 71.1\% (69/97) of nodules were confirmed to be lung adenocarcinoma, with $56.7 \%$ of nodules (55/97) having GGO components, including $39.2 \%$ with pGGO nodules $(38 / 97)$ and $17.5 \%$ with mGGO nodules (17/97); additionally, solid nodules (14/ 97) did not appear to be numerous.

Surgical resection with curative-intent for bilateral nodules had a better survival rate than ipsilateral operation and contralateral combination therapy as well as non-surgical therapy [14]; especially for the nodenegative subgroup [15], this was an appropriate treatment option. In the past, lobectomy was considered a standard surgical treatment for patients with stage I NSCLC [16]. Staged bilateral lobectomy with intervals of 4 to 6 weeks was more feasible in patients with bilateral lung cancers than simultaneous bilateral lobectomy [17]. However, in clinical stage IA lung adenocarcinoma with GGO component $(\mathrm{CTR}<0.5)$, sublobar resection has been shown to be equivalent to lobectomy with regards to survival [18, 19], even for solid nodules [19]. Compared with staged bilateral pulmonary resection, simultaneous bilateral pulmonary resection (L-SL/SL-SL) is considered an effective strategy with shorter postoperative in-hospital stay, similar postoperative complications and duration of chest drain usage [6]. Compared with traditional multi-portal VATS, uniportal VATS has become a safe and feasible technique at our center, with 
Table 3 Comparison of several variables with clinical outcomes

\begin{tabular}{|c|c|c|c|c|}
\hline Variable & $\begin{array}{l}\text { Operative Time } \\
\text { Mean } \pm \text { SD (range) }\end{array}$ & $\begin{array}{l}\text { Chest Tubes } \\
\text { Mean } \pm \text { SD (range) }\end{array}$ & $\begin{array}{l}\text { Hospital Stay } \\
\text { Mean } \pm \text { SD (range) }\end{array}$ & $\begin{array}{l}\text { Complications } \\
\text { n (\%) }\end{array}$ \\
\hline \multicolumn{5}{|l|}{ Age } \\
\hline$>60 y$ & $274.4 \pm 93.4$ & $5.6 \pm 2.4$ & $10.5 \pm 6.9$ & $7(38.9)$ \\
\hline \multirow[t]{2}{*}{$\leq 60 y$} & $247 \pm 89.2$ & $5.6 \pm 2.7$ & $9.8 \pm 4.2$ & $3(17.7)$ \\
\hline & $P=0.387$ & $P=1$ & $P=0.722$ & $P=0.264$ \\
\hline \multicolumn{5}{|l|}{ Lobectomy } \\
\hline Yes & $262.3 \pm 108.1$ & $7.0 \pm 4.1$ & $10.2 \pm 3.6$ & $6(60.0)$ \\
\hline \multirow[t]{2}{*}{ No } & $261.9 \pm 87.5$ & $5.4 \pm 2.1$ & $10.2 \pm 6.4$ & $4(16.0)$ \\
\hline & $P=0.991$ & $P=0.124$ & $P=0.978$ & $P=0.016$ \\
\hline \multicolumn{5}{|c|}{ Systematic lymphadenectomy } \\
\hline Yes & $291.3 \pm 86.6$ & $6.1 \pm 3.1$ & $11.0 \pm 6.44$ & $8(32.0)$ \\
\hline \multirow[t]{2}{*}{ No } & $191.8 \pm 62.4$ & $5.1 \pm 1.5$ & $8.3 \pm 2.9$ & $2(20.0)$ \\
\hline & $P=0.002$ & $P=0.346$ & $P=0.222$ & $P=0.686$ \\
\hline \multicolumn{5}{|l|}{ FEV1/FVC } \\
\hline$>90 \%$ & $238.9 \pm 92.5$ & $6.5 \pm 2.9$ & $11.3 \pm 6.8$ & $7(36.8)$ \\
\hline \multirow[t]{2}{*}{$\leq 90 \%$} & $288.3 \pm 86.2$ & $5 \pm 2.4$ & $9.4 \pm 4.1$ & $3(18.8)$ \\
\hline & $P=0.119$ & $P=0.111$ & $P=0.325$ & $P=0.258$ \\
\hline
\end{tabular}

SD standard deviation, FEV1 preoperative-forced expiratory volume in $1 \mathrm{~s}$, FVC FEV 1 mean forced vital capacity

similar duration of postoperative hospital stay and decreased postoperative thorax drainage [20]. Yao et al. [2] reported that the SL-SL group required less hospitalization after surgery than the L-L/SL group. However, in the present study, there was no significant change in hospital stay between the L-SL group and the SL-SL group.

The optimal surgical methods and suitable timing for synchronous bilateral lung cancer are still debated. Tanvetyanon et al. [21] analyzed 467 patients with multi-lobe synchronous multiple lung cancers. The results revealed that the histology of adenocarcinoma could independently predict the survival rate in multivariate analysis combining histology, sex, age, maximum T-size, highest N-stage, and laterality. They also highlighted that several $\mathrm{N} 0$ and $\mathrm{T}$ sized $\leq 3 \mathrm{~cm}$, patients under 70 years of age, and female sex were favorable survival predictors. This research analyzed survival predictors for surgeons to select appropriate patients; unfortunately, it did not mention the surgical methodswhether single-stage or two-stage. Mun and Kohno [6] suggested a performance status of 3 or higher, when the predicted postoperative FEV 1 was $<800 \mathrm{~mL}$, and bilateral lobectomy recommended staged pulmonary resections. Our research with 35 patients was selected on the premise that patients had good performance status (0-1), an FEV 1/FVC greater than $75 \%$, and were cN0. To the best our knowledge, this is the largest study of surgical outcomes in patients with SMPLCs who underwent simultaneous bilateral pulmonary resection. There was no postoperative 30-day mortality, and the postoperative course was uneventful in $71.4 \%$ of cases. In the current study, the rate of postoperative complications was $28.6 \%(10 / 35)$, including pneumonia $(n=6)$, air leak $(n=1)$, atrial fibrillation $(n=2)$, pneumonia combined with air leak $(n=1)$, and respiratory and cardiac morbidities after the operation had been reported [10]. Of those with postoperative complications, the incidence of pneumonia was higher in the L-SL group than in the SL-SL group with a similar operative time. In the past few years, the duration of surgical resection $(>2 \mathrm{~h}$ ) has presented an increased risk of pulmonary complications [10]; however, in our study-with a similar operative time and higher pneumonia morbidity-simultaneous bilateral SL-SL resection was the preferred therapeutic option compared to simultaneous bilateral L-SL resection, even if both are feasible and safe.

The results of this study indicate that simultaneous bilateral pulmonary resection by uniportal VATS may be a safe and feasible technique for patients with performance status (0-1), FEV 1/FVC more than $75 \%$, and who are cN0. Given these conditions, for SMBPNs with GGO-dominant $(\mathrm{CTR}<0.5)$, it is preferable to opt for simultaneous SL-SL pulmonary resection. For SMBPNs with GGO component (CTR > 0.5) contralateral GGO component $(\mathrm{CTR}<0.5)$, it is preferable to opt for simultaneous L-SL pulmonary resection for selected patients. Additionally, for those patients with poor performance status and pulmonary function testing, a staged resection along with a bilateral lobectomy is preferred. 
Finally, our research had several limitations. First, the selection of patients was biased because this is a singlecenter retrospective study. Second, the sample size was small, as only 35 patients underwent the evaluation. Finally, the follow-up time was short, and the evaluation of long-term survival is lacking. Therefore, multi-center design research with a larger sample size and a longer follow-up time is required to verify our conclusions.

\section{Conclusions}

Simultaneous bilateral pulmonary resections by uniportal VATS is a feasible and safe procedure in appropriate patients. However, simultaneous L-SL pulmonary resections for bilateral nodules can increase the risk of developing pneumonia.

\begin{abstract}
Abbreviations
CT: Computed tomography; SMBPNs: Synchronous bilateral pulmonary nodules; GGO: Ground-glass opacities; SMPLCs: Synchronous multiple primary lung cancers; VATS: Video-assisted thoracic surgery; CTR: Consolidation/tumor ratio; pGGO: Pure ground-glass opacities; mGGO: Mixed ground-glass opacities; sPNs: Solid pulmonary nodules; FEV 1: Forced expiratory volume in $1 \mathrm{~s}$; FVC: Forced vital capacity; L-SL: Lobarsublobar; SL-SL: Sublobar-sublobar; AAH: Atypical adenomatous hyperplasia; AIS: Adenocarcinoma in situ; MIA: Minimally invasive adenocarcinoma; CF: Classification; MPLCs: Multiple primary lung cancers; MMPL

Cs: Metachronous multiple primary lung cancers
\end{abstract}

\section{Acknowledgements}

This work was supported by the Shenzhen Key Medical Discipline Construction Fund (SZXK075), and the Sanming Project of Medicine in Shenzhen (SZSM201612097).

\section{Authors' contributions}

(I) Conception and design: Shengcheng Lin and Chenglin Yang. (II) Administrative support: Zhentao Yu. (III) Provision of study materials or patients: Xiaotong Guo and Lixu Wang. (IV) Collection and assembly of data: Yafei Xu and Zhe Wang. (V) Data analysis and interpretation: Xin Yu and Chunguang Wang. (VI) Manuscript writing: All authors. (VII) Final approval of manuscript: All authors.

\section{Funding}

This work was supported by the Shenzhen Key Medical Discipline Construction Fund (SZXK075), and the Sanming Project of Medicine in Shenzhen (SZSM201612097).

\section{Availability of data and materials} Not applicable.

\section{Declarations}

\section{Ethics approval and consent to participate}

The authors are accountable for all aspects of the work in ensuring that questions related to the accuracy or integrity of any part of the work are appropriately investigated and resolved. The study was conducted in accordance with the Declaration of Helsinki (as revised in 2013). The study was approved by Cancer Hospital \& Shenzhen Hospital, Chinese Academy of Medical Sciences and PeKing Union Medical College Institutional Review Board of Clinical Research. (NO.: 2020-173) and individual consent for this retrospective analysis was waived.

\section{Consent for publication}

Not applicable.

\section{Competing interests}

The authors have no conflicts of interest to declare.

\section{Author details}

'Department of Thoracic Surgery, National Cancer Center/National Clinical Research Center for Cancer/Cancer Hospital and Shenzhen Hospital, Chinese Academy of Medical Sciences and Peking Union Medical College, Shenzhen 518116, China. ${ }^{2}$ Department of Anesthesiology, Shunde Hospital of Southern Medical University (The First People's Hospital of Shunde Foshan), Foshan, China.

Received: 1 November 2020 Accepted: 11 March 2021

Published online: 22 March 2021

\section{References}

1. Zhang Y, Fu F, Chen H. Management of ground-glass opacities in the lung cancer spectrum. Ann Thorac Surg. 2020;110(6):1796-804. https://doi.org/1 0.1016/j.athoracsur.2020.04.094

2. Yao $\mathrm{F}$, Yang $\mathrm{H}$, Zhao $\mathrm{H}$. Single-stage bilateral pulmonary resections by video-assisted thoracic surgery for multiple small nodules. J Thorac Dis. 2016;8(3):469-75. https://doi.org/10.21037/jtd.2016.02.66.

3. Nakata M, Sawada S, Yamashita M, Saeki H, Kurita A, Takashima S, Tanemoto K. Surgical treatments for multiple primary adenocarcinoma of the lung. Ann Thorac Surg. 2004;78(4):1194-9. https://doi.org/10.1016/j.athoracsur.2 004.03.102.

4. Shah AA, Barfield ME, Kelsey CR, Onaitis MW, Tong B, Harpole D, D'Amico TA, Berry MF. Outcomes after surgical management of synchronous bilateral primary lung cancers. Ann Thorac Surg. 2012;93(4):1055-60. https://doi.org/1 0.1016/j.athoracsur.2011.12.070

5. lino K, Oda M, Tsunezuka Y, Ota Y, Watanabe G, Minato H, et al. Treatment for bilateral multiple lung cancers. Kyobu Geka. 2002;55(6):443-8.

6. Mun M, Kohno T. Single-stage surgical treatment of synchronous bilateral multiple lung cancers. Ann Thorac Surg. 2007;83(3):1146-51. https://doi. org/10.1016/j.athoracsur.2006.10.037.

7. Goldstraw P, Chansky K, Crowley J, Rami-Porta R, Asamura H, Eberhardt WE, et al. The IASLC lung Cancer staging project: proposals for revision of the TNM stage groupings in the forthcoming (eighth) edition of the TNM classification for lung Cancer. J Thorac Oncol. 2016;11(1):39-51. https://doi. org/10.1016/j.jtho.2015.09.009.

8. Martini N, Melamed MR. Multiple primary lung cancers. J Thorac Cardiovasc Surg. 1975;70(4):606-12. https://doi.org/10.1016/S0022-5223(19)40289-4.

9. Antakli T, Schaefer RF, Rutherford JE, Read RC. Second primary lung cancer. Ann Thorac Surg. 1995;59(4):863-6. https://doi.org/10.1016/0003-4 975(95)00067-U

10. Miskovic A, Lumb AB. Postoperative pulmonary complications. Br J Anaesth. 2017;118(3):317-34. https://doi.org/10.1093/bja/aex002.

11. Romaszko AM, Doboszynska A. Multiple primary lung cancer: a literature review. Adv Clin Exp Med. 2018;27(5):725-30. https://doi.org/10.17219/a cem/68631.

12. Travis WD, Brambilla E, Noguchi M, Nicholson AG, Geisinger KR, Yatabe $Y$, Beer DG, Powell CA, Riely GJ, van Schil PE, Garg K, Austin JHM, Asamura H Rusch WW, Hirsch FR, Scagliotti G, Mitsudomi T, Huber RM, Ishikawa Y, Jett J, Sanchez-Cespedes M, Sculier JP, Takahashi T, Tsuboi M, Vansteenkiste J, Wistuba I, Yang PC, Aberle D, Brambilla C, Flieder D, Franklin W, Gazdar A, Gould M, Hasleton P, Henderson D, Johnson B, Johnson D, Kerr K, Kuriyama K, Lee JS, Miller VA, Petersen I, Roggli V, Rosell R, Saijo N, Thunnissen E, Tsao $M$, Yankelewitz D. International association for the study of lung cancer/ american thoracic society/european respiratory society international multidisciplinary classification of lung adenocarcinoma. J Thorac Oncol. 2011;6(2):244-85. https://doi.org/10.1097/JTO.0b013e318206a221.

13. Chen K, Chen W, Cai J, Yang F, Lou F, Wang X, Zhang J, Zhao M, Zhang J, Wang $J$. Favorable prognosis and high discrepancy of genetic features in surgical patients with multiple primary lung cancers. J Thorac Cardiovasc Surg. 2018;155(1):371-9. https://doi.org/10.1016/j.jtcvs.2017.08.141.

14. Zhou H, Kang X, Dai L, Yan W, Yang Y, Lin Y, Chen KN. Efficacy of repeated surgery is superior to that of non-surgery for recurrent/second primary lung cancer after initial operation for primary lung cancer. Thoracic Cancer. 2018; 9(8):1062-8. https://doi.org/10.1111/1759-7714.12790.

15. Voltolini L, Rapicetta C, Luzzi L, Ghiribelli C, Paladini P, Granato F, Gallazzi M, Gotti G. Surgical treatment of synchronous multiple lung cancer located in a different lobe or lung: high survival in nodenegative subgroup. Eur J Cardiothorac Surg. 2010;37(5):1198-204. https://doi.org/10.1016/j.ejcts.2009.11.025. 
16. Ginsberg RJ, Rubinstein LV. Randomized trial of lobectomy versus limited resection for T1 N0 non-small cell lung cancer. Lung Cancer study group. Ann Thorac Surg. 1995;60(3):615-22. https://doi.org/10.1016/0003-4 975(95)00537-U.

17. Hattori A, Suzuki K, Takamochi K, Oh S. Is bilateral pulmonary lobectomy feasible in patients with bilateral lung cancers? Thorac Cardiovasc Surg. 2015;63(7):589-96. https://doi.org/10.1055/s-0034-1383816.

18. Subramanian M, McMurry T, Meyers BF, Puri V, Kozower BD. Long-term results for clinical stage IA lung Cancer: comparing lobectomy and sublobar resection. Ann Thorac Surg. 2018;106(2):375-81. https://doi.org/10.1016/j.a thoracsur.2018.02.049.

19. Altorki NK, Yip R, Hanaoka T, Bauer T, Aye R, Kohman L, Sheppard B, Thurer R, Andaz S, Smith M, Mayfield W, Grannis F, Korst R, Pass H, Straznicka M, Flores R, Henschke CI, I-ELCAP Investigators. Sublobar resection is equivalent to lobectomy for clinical stage $1 \mathrm{~A}$ lung cancer in solid nodules. J Thorac Cardiovasc Surg. 2014;147(2):754-62. https://doi.org/10.1016/j.jtcvs.2013.09.065.

20. Li J, Qiu B, Scarci M, Rocco G, Gao S. Uniportal video-assisted thoracic surgery could reduce postoperative thorax drainage for lung cancer patients. Thoracic Cancer. 2019;10(6):1334-9. https://doi.org/10.1111/17597714.13040.

21. Tanvetyanon T, Finley DJ, Fabian T, Riquet M, Voltolini L, Kocaturk C, Bryant A, Robinson L. Prognostic nomogram to predict survival after surgery for synchronous multiple lung cancers in multiple lobes. J Thorac Oncol. 2015; 10(2):338-45. https://doi.org/10.1097/JTO.0000000000000400.

\section{Publisher's Note}

Springer Nature remains neutral with regard to jurisdictional claims in published maps and institutional affiliations.

Ready to submit your research? Choose BMC and benefit from:

- fast, convenient online submission

- thorough peer review by experienced researchers in your field

- rapid publication on acceptance

- support for research data, including large and complex data types

- gold Open Access which fosters wider collaboration and increased citations

- maximum visibility for your research: over $100 \mathrm{M}$ website views per year

At $\mathrm{BMC}$, research is always in progress.

Learn more biomedcentral.com/submissions 